\title{
NOCIÓN Y ELEMENTOS FUNDAMENTALES DE LA ACCIÓN TERRITORIAL CONJUNTA
}

\author{
CONCEPT AND FUNDAMENTAL ELEMENTS OF JOINT \\ TERRITORY ACTION
}

\begin{abstract}
Benô̂T Delooz*
RESUMEN: El concepto de Acción Territorial Conjunta puede ayudar a superar algunos problemas fundamentales de gestión administrativa, surgidos de la dicotomía centralizacióndescentralización, y de la conciliación entre territorialización y funcionalización de los entes públicos.
\end{abstract}

Palabras clave: Descentralización, coadministración, planificación territorial, convenios interadministrativos.

ABSTRACT: The concept of Joint Territorial Action can help overcome some fundamental problems of administrative management, emerged from the centralization-decentralization dichotomy, and the conciliation between territorialization and functionalization of public entities.

Key words: Decentralization, coadministration, territorial planning, Inter-administrative agreements.

\section{INTRODUCCIÓN}

El Estado de Chile es unitario y su organización territorial se articula en torno a las nociones de desconcentración, descentralización y desarrollo equitativo y solidario entre entes territoriales (en adelante, ET), conforme el artículo 3 de la Constitución Política de la República (CPR, en adelante). La noción jurídica tradicional de descentralización, y sus avatares administrativos y políticos, son insuficientes para explicar la complejidad de la situación chilena actual (y futura). En efecto, constatan principalmente que el Estado no se rige de manera exclusivamente centralizada, sino que acepta y ordena un pluralismo normativo. En ese sentido, las condiciones de su realización se limitan según la doctrina clásica a la elección de las autoridades de los ET, sus competencias y sus recursos. Pero, no bastan para explicar el grado de autonomía real de los ET. El concepto de acción territorial conjunta (en adelante ATC) puede ayudar a estructurar y precisar -jurídicamente- la reflexión sobre los procesos descentralizadores y especialmente la situación chilena.

\footnotetext{
* Docteur en Droit public de l'Université de Toulouse 1 Capitole y Doctor en Derecho por la Universidad de Chile. Profesor de Derecho público en el Instituto de Investigación en Derecho (IID) - Universidad Autónoma de Chile. Dirección postal: Pedro de Valdivia 425, Providencia. Dirección electrónica: benoit.delooz@uautonoma.cl. Este trabajo constituye el artículo introductorio del proyecto de investigación Fondecyt Iniciación No 11160082 , Teoría y práctica jurídica de la Acción Territorial Conjunta, del cual el autor es investigador responsable.
} 
El presente artículo aborda la problemática de la acción de las personas públicas sobre el territorio. Su punto de partida es la hipótesis según la cual la identificación del concepto de ATC puede ayudar a superar algunos problemas fundamentales relativos a las instituciones públicas en particular, y al derecho público en general: la oposición entre centralización y descentralización, la conciliación entre territorialización y funcionalización de los entes públicos y, en fin, los cuestionamientos sobre las grandes categorías del derecho administrativo, que son el acto administrativo unilateral y el contrato administrativo.

En una primera sección se abordará la noción (I) y los fundamentos (II) de la ATC. Luego, se presentarán los principios de gestión administrativa que guían su diseño y la actuación de las personas públicas territoriales (III). Esta se realiza mediante instrumentos de planificación territorial e instrumentos de índole contractual, dentro de los cuales destacan los convenios de programación (en adelante CP), que revisten para Chile una importancia primordial en la elaboración y realización de las políticas territoriales (IV). Es necesario considerar lo que son y lo que significan.

\section{NOCIÓN}

La noción de ATC no existe como tal, en derecho positivo chileno, pues solo encontramos una referencia remota al concepto en el artículo 110 de la Ley Orgánica Constitucional de Gobierno y Administración Regional (LOCGAR, en adelante), que menciona las “acciones municipales conjuntas". Algunos autores la han evocado de manera incidental ${ }^{2}$, o con referencia expresa al régimen municipal. Así, se afirma que "la multiplicidad de organismos públicos que intervienen en la satisfacción de las necesidades de la población, redunda en la imperiosa necesidad de una acción conjunta, coordinada y coherente, que permita la gestión eficiente y ordenada de los recursos públicos acorde con el principio de unidad de acción”3. Por su parte, el Informe de Comisión Asesora Presidencial en Descentralización y Desarrollo Regional de 2014 menciona la acción común en dos oportunidades: a propósito de la igualdad horizontal territorial, y del principio de coordinación. Señala -parafraseando el artículo 72 inc. 5 de la Constitución francesa- que "cuando el ejercicio de una competencia requiera de la acción concertada de varias entidades territoriales autónomas, la ley debe posibilitar que dichas entidades organicen las modalidades de su acción común”․ Tal similitud autoriza una remisión a la experiencia francesa, pues como disposición constitucional es objeto de la labor legislativa, administrativa, jurisdiccional y doctrinal. En este sentido, la noción de articulación de las competencias ${ }^{5}$ o de

\footnotetext{
1 Por su parte, el artículo $4^{\circ}$ de la Ley Orgánica de Municipalidades (LOCM), en adelante) menciona dentro de las competencias compartidas de las municipalidades, "l) El desarrollo de actividades de interés común en el ámbito local".

2 Por ej. Cordero (2007) p. 283.

3 Villagrán (2013) p. 205.

4 Comisión Asesora Presidencial en Descentralización y Desarrollo Regional (2014) pp. 17 y 29.

5 Moreau (2004) p. 17.
} 
acción común ${ }^{6}$ toma cada día más fuerza. La ATC se sitúa a la intersección de las diferentes ramas del derecho público (constitucional y administrativo) y, de manera general, se refiere al ordenamiento (y desarrollo) territorial 7 , y a sus ramas principales que son el derecho urbanístico y la planificación territorial socioeconómica ${ }^{8}$, sin olvidar las consideraciones medioambientales'.

\section{FUNDAMENTOS}

\subsection{LA EXIGENCIA DE COHESIÓN}

Como se ha señalado, "es un axioma de la ciencia política y del Derecho público que todo Estado necesita un grado suficiente de cohesión interna. No solo el Estado, sino cualquier otra unidad política, supra o infraestatal"10. Debe ser una cohesión social, cultural, y económica, pero debe ser también una "cohesión institucional, entendida como aquel conjunto de reglas, valores, principios y actitudes de las distintas instituciones públicas y de los diferentes niveles de gobierno y administración, relativas a sus relaciones recíprocas, que permitan un regular y ordenado funcionamiento de todos ellos para la consecución de los fines que constitucionalmente les están atribuidos"11.

La exigencia de cohesión resulta de diferentes mandatos constitucionales del Capítulo I relativo a las Bases de la institucionalidad ${ }^{12}$. En primer lugar, el Estado está al servicio de la persona humana y su finalidad es promover el bien común, para lo cual debe contribuir a crear las condiciones sociales que permitan a todos y a cada uno de los integrantes de la comunidad nacional su mayor realización espiritual y material posible (art. 1, inc. 3). Luego, esa cohesión del cuerpo social se debe realizar en un Estado unitario, desconcentrado y descentralizado (art. 3, inc. 1). Eso significa que debe fomentar las autonomías

\footnotetext{
6 Ver por ejemplo: Briant (2009). El autor considera en su obra lo que llama la "acción común" como elemento constitutivo de la descentralización territorial, partiendo de la idea que la descentralización territorial es autonomía y coadministración (o cooperación). Si nos hacemos cargo de algunas de sus conclusiones, difiero sobre el hecho que el autor tiende a considerar las políticas públicas territoriales como una actividad esencialmente coproducida, basada sobre una lógica de negociación permanente e incesante. Tal negociación es innegable desde un punto de vista de sociología jurídica o de ciencia política y a nivel legislativo, pero la aplicación de las leyes necesita aún del acto jurídico unilateral.

7 En ese sentido, "debe observarse que tanto la Constitución como la LOCGAR van más allá del campo de la planificación urbana, que es la materia que básicamente regula la LGUC. En efecto, ambos se refieren al territorio (desarrollo territorial y ordenamiento territorial). La dimensión "urbana" excluye a la "rural", pero la "territorial”, en cambio, comprende tanto el área rural como la urbana." RAJEVIC (2000) p. 534. La Carta Europea de Ordenación del Territorio (1983) afirmó que el concepto de ordenación del territorio "es a la vez una disciplina científica, una técnica administrativa y una política concebida como un enfoque interdisciplinario y global, cuyo objetivo es un desarrollo equilibrado de las regiones y la organización física del espacio según un concepto rector." Luego, señala que "la ordenación del territorio debe ser democrática, global, funcional y prospectiva".

8 Ya el considerando $1^{\circ}$ del DL No573 de 1974.

9 Como se sabe, ninguno de los instrumentos de planificación territorial puede hoy ser aprobado sin ser previamente evaluado a través del Sistema de Evaluación de Impacto Ambiental. Ver, por ejemplo: Bermúdez (2014), ROJAS (2012).

10 SÁNCHez (1992), p. 13.

11 SÁNCHEZ (1992), p. 13.

12 Resulta también esclarecedor el art. 14 LOCGAR.
} 
regionales y locales, es decir entregar competencias y recursos materiales como financieros a autoridades elegidas democráticamente. Pero, el pluralismo institucional y normativo inherente a la descentralización, implica y/o refuerza las desigualdades entre ET y habitantes. Es entonces una necesidad para el Estado organizar la cooperación territorial en razón de varios factores ${ }^{13}$ que justifican medidas de desarrollo económico y social, como de solidaridad territorial o de protección del medio ambiente. En cuanto al concepto de solidaridad territorial ${ }^{14}$, "para el gobierno y administración interior del Estado [...] se observará como principio básico la búsqueda de un desarrollo territorial armónico y equitativo. Las leyes que se dicten al efecto deberán velar por el cumplimiento y aplicación de dicho principio, incorporando asimismo criterios de solidaridad entre las regiones, como al interior de ellas, en lo referente a la distribución de los recursos públicos" ${ }^{15}$. Esquemáticamente cabe destacar el papel precursor de las políticas de ordenamiento territorial, el auge de las preocupaciones ambientales, y los mecanismos financieros de aquella solidaridad. Dentro de estos últimos, destacan los fondos de compensación territorial ${ }^{16}$ o de redistribución solidaria o equitativa $^{17}$, hoy constitucionalizados ${ }^{18}$. Estos fondos tienen por objeto remediar las desigualdades entre ET, las cuales a menudo se incrementaron por la autonomía otorgada. Por ello, la redistribución equitativa horizontal resuena como un eslogan, o un voto piadoso, más que como una posibilidad real, pues incluso en la estructura más descentralizada, es necesario un centro que mantenga la cohesión del conjunto. En ese sentido, los fondos de redistribución equitativa vertical tradicionales son insuperables. En fin, como he señalado, por sus implicancias sobre el desarrollo sustentable y las futuras generaciones, no se pueden eludir las preocupaciones por el derecho a un medio ambiente libre de contaminación ${ }^{19}$. Las políticas públicas relativas a esos objetivos constitucionales son reveladoras del carácter mixto de los asuntos públicos. A modo de ejemplo, se puede recoger el listado de las competencias compartidas de las municipalidades o de las funciones del Gobierno Regional. El desarrollo económico y social de los territorios implica varias dimensiones estrechamente asociadas: los grandes equilibrios de la Nación a cargo del Estado (fiscalidad, moneda, control de los precios, enseñanza); el acompañamiento y la supervisión de los proyectos depende de los ET (servicios públicos, transportes, fiscalidad local o regional, inversiones públicas como privadas $)^{20}$; y, en fin, el dinamismo de las propias empresas condiciona la modernización de las administraciones públicas y la competitividad. La solidaridad movi-

\footnotetext{
13 Situación financiera global de Chile, desigualdades territoriales, finanzas regionales.

14 Art. 3, inc. 2 CPR.

15 Art. 115 inc. 1 CPR.

16 La SUBDERE define el FNDR como "un programa de inversiones públicas, con fines de compensación territorial, destinado al financiamiento de acciones en los distintos ámbitos de infraestructura social y económica de la región, con el objetivo de obtener un desarrollo territorial armónico y equitativo". http://www.subdere. $\mathrm{cl} /$ documentacion/caracter\%C3\%ADsticas-del-fondo-nacional-de-desarrollo-regional-fndr, consultado el $30 / 01 / 2017$.

17 Se pueden citar también los impuestos locales; las devoluciones e incitaciones fiscales; la globalización de los recursos; los aportes estatales por la ley de presupuesto.

18 Art 115 inc. 2 CPR.

19 Art. 19, No 8 CPR.

20 Sobre ese punto, ver por ejemplo los arts. 4 LOCM; 16 y18 LOCGAR.
} 
liza la acción social contra cualquiera forma de exclusión y las municipalidades están mandatadas para actuar en el terreno social y, particularmente, luchar contra la pobreza. No obstante, el problema de la efectividad de tales misiones reside en la escasez de los recursos a disposición de casi la totalidad de aquellas. Para remediar tal situación, la LOCM señala como funciones compartidas (art. 4), a) la educación y la cultura; b) la salud pública; c) la asistencia social y jurídica; g) la construcción de viviendas sociales e infraestructuras sanitarias; i) la prevención de riesgos y la prestación de auxilio en situaciones de emergencia o catástrofes ${ }^{21}$. El medio ambiente ${ }^{22}$, por su parte, constituye una dimensión de cualquier acción pública que involucra varias autoridades en grados diversos ${ }^{23}$. Al respecto, el Servicio de Evaluación Ambiental "coordina a todas las administraciones públicas con competencia ambiental en la medida que considera la participación y el trabajo conjunto del titular del proyecto, de las autoridades públicas, y de la comunidad organizada así como de las personas naturales directamente afectadas por el proyecto" ${ }^{24}$. En el marco de una reflexión sobre la ATC -como noción y herramienta de medición del grado de descentralización administrativa del que benefician los ET según una actividad dada- es necesario considerar como se articula (o concilia) la exigencia de cohesión con la de coherencia de la acción pública.

\subsection{LA NECESIDAD DE COHERENCIA ${ }^{25}$}

\subsubsection{El eterno problema de la repartición de las competencias}

Salvo algunas excepciones, ninguna competencia descentralizada es realmente especializada por niveles de administración territorial, y la mayoría están compartidas entre ET, o entre ellos y el Estado. La búsqueda de claridad conduce el legislador a consagrar competencias exclusivas, pero que, en la práctica, resultan ser la excepción. "Por el contrario, es mucho más frecuente la tangencialidad, la compartición, la concurrencia o el entrecruzamiento de las competencias. No solo en nuestro sistema constitucional, sino prácticamente en todos, ya que en el Estado intervencionista, ni los poderes centrales, ni los periféricos pueden o quieren desentenderse de actuar en las grandes áreas económicas, sociales o medioambientales, a las que son reconducibles o con las que guardan puntos de contacto la mayoría de las competencias públicas. En una situación semejante adquiere nueva importancia el problema de las relaciones organizativas entre las Administraciones públicas (y en el seno de cada una de ellas)"26; y se ha demostrado desde mucho tiempo la dificultad de una definición a priori de la competencia material de los ET: "la repartición de las competencias entre el Estado y las colectividades locales es un problema falsamente técnico. Es una cuestión de filosofía política que traduce el sitio reconocido a los ET en la nación”27.

\footnotetext{
21 A nivel regional, ver el art. 19 LOCGAR relativo al desarrollo social y cultural, que marca quizás aún más el carácter conjunto de las funciones del gobierno regional.

22 Por todo, ver Bermúdez (2014); Astorga (2006); GuZmán (2010); Varela (2010).

23 Cf. artículo $8^{\circ}$, inc. 3 a 5, Párrafo $2^{\circ}$ LGBMA

24 ROJAS (2012) p. 251.

25 Para una aproximación de la coherencia desde la teoría general del derecho, ver: BobBio (2007) pp.180-212.

26 SÁnchez (1992) p. 15.

27 Pontier (1978) p. 572.
} 
Es una cuestión contingente. A partir de eso, la consagración de la noción de articulación de las competencias cuestiona los procesos de descentralización de los Estados unitarios. ¿Se trata de una técnica de recentralización? o ¿se debe ver el reconocimiento de un sistema evocado en otro lugar?: la descentralización cooperativa. Este concepto más cercano a casos como Italia, aún está lejos de aplicarse en Chile. Mientras, la ATC se impone por la imposibilidad de establecer una distribución de competencias clara y clausurada.

\subsubsection{La voluntad de subsidiariedad}

En el caso de la subsidiariedad, las competencias se ejercen en la base, con excepción de las que son retenidas a nivel superior. En la descentralización, las competencias generales (o de principio) residen en el gobierno central, y los escalones inferiores solo asumen competencias atribuidas. Presentado como la panacea a todos los males de la descentralización, ya hemos señalado sus aporías en un Estado unitario ${ }^{28}$, subrayando más lo qué es, que lo que quisieran que fuera sus turiferarios: siguiendo a Derosier, más allá de un deseo piadoso de buena gobernanza, más que un verdadero principio jurídico, es un principio técnico y democrático de legitimación de la descentralización como de la centralización. Significa que es un principio de esclarecimiento de la dialéctica centralización/descentralización $^{29}$. Varios argumentos invitan a matizar las promesas del principio de subsidiariedad. Primero, se puede preguntar si no existe una contradicción entre este principio (y con ello, entre el de solidaridad) y el principio de los traspasos de competencias. Transferir de manera unilateral y, a veces, autoritaria algunas competencias a los ET (y menos regularmente a petición), ¿no entra en conflicto con una aplicación flexible del principio que supondría una libertad de elección de parte de tales entes? ${ }^{30}$. Ahora bien, el legislador no deja a los mismos ET libres para determinar lo que pueden, o no, hacer. Por otra parte, la acción pública territorial que se ejecuta cada vez más de manera conjunta, se combina mal con las preocupaciones de subsidiariedad, que llaman un cierto nivel de protección de las competencias ${ }^{31}$. Luego, si se piensa en el principio de subsidiariedad como una herramienta de acercamiento a una estructura federalizada, en este caso, el principio puede aplicarse porque son las células de base que disponen de las competencias generales o de principio. Todo lo contrario de la situación chilena.

Los fundamentos de la ATC conducen a una reflexión sobre el ejercicio mismo del poder. De manera esquemática, o se aboga por algunas prácticas que tienen que ver -en lo esencial- con la subsidiariedad, es decir que cada responsable solo debería intervenir si nadie está mejor posicionado que él (hemos visto las dificultades materiales como normativas). O el conjunto de los poderes públicos responsables actúan mediante convergencia, para contribuir a la obra común para la cual los ciudadanos solicitan y exigen cada vez más participación. Hoy, administrar el territorio supone estrategias que implican comprender, vivir y actuar en conjunto.

\footnotetext{
Delooz (2015).

9 Derosier (2007).

Wollmann (2006) p. 129.

31 Auby (2009) p.19.
} 
Para comprender en conjunto, se debe buscar coherencia y claridad. Se logra mediante la concertación. Regularmente bajo la égida del Estado que organiza y arbitra los procedimientos de codecisión. Pero, también, por el contrato, o cualquiera fórmula jurídica que permite compartir los objetivos y recursos.

Para vivir juntos, se impone una lógica de solidaridad, la cual puede ser tanto natural como voluntaria, y creada por ley. En el primer caso, hablamos de las dos colectividades públicas que se constituyen, o para la vida cotidiana (los municipios), o para la cohesión de un modelo de sociedad política (el Estado). En el segundo, se considera una aproximación voluntaria de la solidaridad para gestionar los servicios públicos y son constituidas por la CPR o la ley: se tratará de ET intermediarios (regiones) o fórmulas de cooperación (áreas metropolitanas, asociaciones y fundaciones municipales y regionales).

En fin, para actuar en conjunto, es necesaria una mente colaborativa. Para intentar poner orden y armonía entre esos diferentes elementos, es necesario tener principios de acción.

\section{PRINCIPIOS Y MODALIDADES DE ACCIÓN}

La "Administración es 'objeto de dirección', y ello en la medida en que las fuerzas de producción normativa a nivel nacional (y europeo) a través del Derecho le deben otorgar la habilitación precisa e imponer las obligaciones necesarias para que aquella pueda atender sus funciones"32. Pero, para delimitar mejor los componentes de la ATC, comprendemos que se trata de una codirección por parte del Parlamento y del Ejecutivo principalmente, este último entendido, aquí, en su función de gobierno-colegislador y no como Administración ${ }^{33}$. Esa labor de codirección debe ser apreciada tanto desde el punto de vista de los procedimientos legislativos, como de los resultados. Es decir, el peso respectivo de los colegisladores en la formulación de las políticas descentralizadoras, pero sobre todo los ámbitos de competencias administrativas transferidas y transferibles, así como una tipología de esas y sus caracteres.

Para precisar el sentido de codirección, puede ser de utilidad transponer al ámbito constitucional la concepción de las relaciones de dirección internas a cada Administración. Permitirá distinguirla de los principios de acción de la Administración en el marco de la ATC. Para SÁnchez Morón, "por relaciones de dirección se entiende aquí una fórmula de supremacía-subordinación entre órganos o entre entes públicos más flexible que la jerarquía, pues se funda esencialmente en la adopción por el superior de directrices, programas

\footnotetext{
32 Schmidt-Assmann (2003) p. 28. Seguidamente, el autor precisa que la Administración "es al mismo tiempo "sujeto de dirección", que transpone de forma activa los impulsos directivos, y lleva a cabo actividades propias para la dirección de los distintos sectores sociales en el marco de la legalidad." Ibídem. Por nuestra parte, esa misión de dirección corresponde más bien a lo que llamamos la coordinación administrativa. Cf. infra.

33 AylWin (1959) p. 15. También Pantoja (1994) p. 151. "La distinción entre la función de gobierno y de administración proviene del constitucionalismo clásico del 1800. Constituyó la fórmula de otorgar al jefe de Estado un ámbito de libre decisión paralelo a su poder ejecutivo".
} 
o instrucciones generales vinculantes, a completar o desarrollar por el subordinado, y no comprende otras manifestaciones típicas de las relaciones jerárquicas" ${ }^{\prime 4}$.

Si las modalidades de la ATC (y su definición legal eventual) dependen del legislador, importa a la doctrina participar en ese debate, sea sintetizando lo existente, sea llamando la atención sobre algunos elementos que el legislador podría o debería tomar en cuenta. En este sentido, es ineludible el análisis de la conjunción del concepto de coordinación, marcado por una visión unilateral de dirección de las colectividades públicas, con las nociones de cooperación, y participación - estas, más bien caracterizadas por la irrupción del contrato y de los mecanismos consultivos. Es esa conjunción la que permite hablar de ATC. Ese último adjetivo que remite a la idea de mezcla y/o de incorporación ${ }^{35}$, abarca la diversidad de las combinaciones de los procedimientos decisionales que intervienen en la gestión de los territorios. Cabe distinguirlas porque el legislador como la Administración, o confunden un término por otro, o directamente los asimila. La confusión conduce a que el legislador pueda querer realmente descentralizar, pero en la práctica no se da cuenta de que sus leyes y/o sus reglamentos de aplicación, traslucen a lo menos una confusión, o tal vez algo peor, una recentralización que quería combatir. El uso indiscriminado de un término por otro por parte del constituyente o legislador; o el rango normativo que consagra (cuando lo hace) tal o cual principio, sin hablar de sus sanciones eventuales por parte de los órganos constitucionales o jurisdiccionales, conducen a situaciones confusas, conflictivas y una desconsideración del legislador. En fin, se descarta aquí el uso del término de colaboración, frecuentemente asociado al de cooperación, porque puede estar asociado a los tres principios de actuación mencionados y, luego, es más un deber -de difícil control y sanción- y una necesidad ${ }^{36}$, que un principio o mecanismo tangible de actuación administrativa $^{37}$.

\subsection{LA COORDINACIÓN ADMINISTRATIVA COMO TÍTULO COMPETENCIA}

Fiel a los objetivos de cohesión y coherencia, la LOCBGAE dispone que los órganos de la Administración del Estado deberán cumplir sus cometidos coordinadamente y propender a la unidad de acción, evitando la duplicación o interferencia de funciones. El término mismo de coordinación es recogido por la propia $\mathrm{CPR}^{38}$ y los cuerpos legislativos más importantes, como por leyes sectoriales ${ }^{39}$. Por su parte, el Diccionario de Administración pública chilena la define como la "actividad destinada a integrar y armonizar los recursos

\footnotetext{
34 SÁnChez (92), nota pie 12, p. 18.

35 Ver la voz (sentido 2) de "conjunta" en el diccionario de la Real Academia de la Lengua española.

36 Efectivamente, hay forzadamente colaboración en la coordinación-que sea voluntaria o no- de una actividad, en la cooperación para lograr algo, y en la participación que per se es una colaboración.

37 Además, el término colaboración no aparece en la CPR; dos veces en la LOCGBAE: arts. $1^{\circ}$ y 22; ninguna vez en la LBPA; y una vez en la LOCGAR: art. 68.

38 Arts. 33 inc. 3 ; 64 inc. 5; 112 inc. 1 ; 118 inc. 8; 123.

39 Arts. 3 y 5 LOCBGAE; LOCGAR: arts. 2 j) y n); 17 b) y d); 18 b); 19 b); 24 l); 45 e); 62 inc. 1 ; 64 a), c) y f); 109 inc. 1, y 110; LOCM: arts. 7, 10, 23 b), 26 b); 29; 31 y 63 k) y l); 102 inc. 3; 137 f); LGUC: arts. 40; $49 ; 79$.
} 
y actividades hacia el logro de los objetivos propuestos" ${ }^{40}$. Resulta que es "una necesidad derivada de la propia estructura del Estado que, aun siendo descentralizada, constituye una unidad, correspondiendo por tanto a este la labor de coordinación" ${ }^{\prime 1}$. Además, la CPR señala primero, que es un deber constitucional del Estado asegurar "la coordinación y control de las acciones relacionadas con la salud" ${ }^{42}$; luego, una técnica de gestión de la Administración centralizada, puesto que el Presidente puede "encomendar a los Ministros coordinar la labor que corresponde a los Secretarios de Estado y las relaciones del Gobierno con el Congreso Nacional" ${ }^{43}$. Pero es también un deber de gestión de la administración desconcentrada, puesto que "al intendente le corresponderá la coordinación, supervigilancia o fiscalización de los servicios públicos creados por ley para el cumplimiento de las funciones administrativas que operen en la región” ${ }^{4}$; $y$, en fin, una técnica de gestión de la Administración descentralizada que permite que la ley establezca "fórmulas de coordinación para la administración de todos o algunos de los municipios, con respecto a los problemas que les sean comunes, así como entre los municipios y los demás servicios públicos” ${ }^{35}$. PANTOJA identificó el principio de coordinación como uno de los dos grandes principios originarios junto con el de competencia de la organización de la Administración ${ }^{46}$. Sin embargo, a mi juicio, la coordinación es una competencia -como lo demuestran los ejemplos precedentes- y resulta artificial aquella distinción. Lo anterior se confirma si entendemos que "jerarquía y tutela administrativa, como principios o conceptos sintéticos que resumen y dan sentido a un conjunto de técnicas relacionales bien conocidas, están siendo sustituidos por los de dirección y coordinación” ${ }^{47}$. En el campo intraadministrativo, es decir, en el seno de una misma administración, la coordinación de los servicios se hace normalmente mediante la vía jerárquica y no necesita, en rigor, considerar las preocupaciones personales de los subordinados.

Ahora bien, la noción de coordinación como la de tutela traducen un poder jurídico (de coordinación, de tutela), esto es, una competencia. Eso significa que, conforme a los principios de la tutela, pero sobre todo al principio de derecho público de competencias, la competencia de coordinación debe estar expresamente atribuida ${ }^{48}$. Siguiendo el paralelo con la tutela, el poder de coordinación supone la alteridad, y su utilización dentro de una misma persona jurídica es incongruente, pues para ello existen las circulares y el poder jerárquico en sus diferentes manifestaciones ${ }^{49}$. Tampoco puede (o no debería) ser utilizado

\footnotetext{
40 SUBDERE (2002) p. 14: Voz “Administración: (adm.) 3.) Coordinación”.

41 Rodríguez-Arana (2006) p. 150.

42 Art. 19-9, inc. 3 CPR.

43 Art. 33, inc. 3 CPR.

44 Artículo 112, inc. 1 CPR.

45 Disposiciones Generales, Art. 123 CPR.

46 Pantoja 2004.

47 SÁNCHez (1992) p. 19.

48 Art. 6 y 7 CPR.

49 BERMÚdEZ señala que en general las facultades o poderes de jerarquía incluyen un poder de impulsión, un poder de dirección que se manifiesta a través de instrucciones y directivas, un poder de inspección, vigilancia o control que consiste en la facultad de revisar a cualquier momento la acción del órgano inferior, un poder de anulación de los actos del órgano inferior, un poder disciplinario, un poder de delegación de competencias y el
} 
para disminuir la autonomía de los ET, es decir, ejercer controles de legalidad y/o de oportunidad, para corregir una acción o sustituir la inacción de las autoridades coordinadas. En ese sentido, es cuestionable el artículo 10 LOCM que reconoce a un órgano desconcentrado del Presidente de la República (el gobernador provincial) un poder de substitución a la inacción o la mala voluntad de las municipalidades, pues señala que "la coordinación entre las municipalidades y entre estas y los servicios públicos que actúen en sus respectivos territorios, se efectuará mediante acuerdos directos entre estos organismos. A falta de acuerdo, el gobernador provincial que corresponda dispondrá las medidas necesarias para la coordinación requerida, a solicitud de cualquiera de los alcaldes interesados. En todo caso, la coordinación deberá efectuarse sin alterar las atribuciones y funciones que correspondan a los organismos respectivos".

Primero, se notará que el uso del término de "coordinación" es inapropiado, pues si se debe "efectuar mediante acuerdos directos entre estos organismos", se trata de una cooperación. Luego, no se advierte como el gobernador provincial dispondría las medidas necesarias para la coordinación requerida sin alterar las atribuciones y funciones de las municipalidades. Efectivamente, se podría decir que "acordar directamente" manifiesta la "autonomía de la voluntad" de los municipios, e imponer un comportamiento a otro, es inmiscuirse en sus asuntos, es decir, alterar sus competencias. La coordinación para lograr la ATC toma entonces la forma de los actos normativos unilaterales: principalmente la ley y el reglamento. Sin embargo, resulta que no son simplemente guías destinadas a apoyar una mejor gestión concertada y deliberada de los territorios: incluso respecto a las atribuciones propias o funciones privativas de las municipalidades, estas deben actuar sometiéndose a las instrucciones y normas técnicas ministeriales. Lo que sin ser una tutela administrativa o jurisdiccional, constituye una forma de tutela técnica. Así, detrás de la misión de coordinar se esconden las tendencias autoritarias y centrípetas del poder. La frontera es débil entre la buena idea y su desviación. Sin duda, una manera de prevenir este escollo sería hacer participar a los ET en la definición de las normas de coordinación.

El derecho público es, por esencia, no igualitario. La Administración está al servicio de la persona humana y su finalidad es promover el bien común ${ }^{50}$. Para asegurar su satisfacción, dispone de prerrogativas de potestad pública, dentro de las cuales figura en primer lugar la decisión ejecutoria, el acto administrativo unilateral. Seguramente, el fenómeno contractual toma cada día más fuerza, pero los instrumentos de planificación territorial atestiguan la permanencia del dirigismo y de la unilateralidad de la acción pública. Además, son claros los mecanismos de tutela de los órganos centrales sobre los órganos no centrales. La coordinación tiene una vertiente institucional y normativa.

En cuanto a la coordinación institucional, "la búsqueda de un desarrollo territorial armónico y equitativo" ${ }^{51}$ es el principio básico que debe guiar el gobierno y administración interior del Estado. La creación de instituciones públicas para coordinar las acciones de los

poder de resolver los conflictos de competencias entre órganos inferiores. BERMúdEz (2011) pp. 322-323. También: SiLVA (1994) p. 44.

50 Art 1 , inc. 3 CPR.

51 Art. 115 inc. 1 CPR. 
ET o para asegurar la gestión de recursos dedicados a la cooperación vertical u horizontal, nacional o no, es una necesidad ${ }^{52}$. A nivel nacional, el conjunto de los ministerios está concernido según su campo de intervención, pero toma particular relevancia el Ministerio del Interior y su Subsecretaría de Desarrollo Regional y Administrativo (en adelante SUBDERE). A nivel regional, cabe mencionar el Delegado Presidencial Regional (ex Intendente regional $)^{53}$-y su órgano desconcentrado, el Delegado Presidencial Provincial- y las secretarías regionales ministeriales (en adelante SEREMI). Al respecto, el nuevo artículo 115 bis $\mathrm{CPR}^{54}$ confirma que "al delegado presidencial regional le corresponderá la coordinación, supervigilancia o fiscalización de los servicios públicos creados por ley para el cumplimiento de las funciones administrativas que operen en la región que dependan o se relacionen con el Presidente de la República a través de un Ministerio". A su vez, el artículo 64 de la LOCGAR deja establecido de la manera más clara posible, el papel de coordinación de las SEREMI, así como su misión de control general sobre la vida regional.

Respecto a los mecanismos normativos de coordinación, más allá de las disposiciones constitucionales y legales, cabe mencionar las circulares de la División de Desarrollo Urbano (en adelante DDU). Instituidas por el artículo 4 de la Ley General de Urbanismo y Construcciones y su Ordenanza General, "tienen como propósito, impartir instrucciones sobre la aplicación de las disposiciones de la Ley General de Urbanismo y Construcciones y su Ordenanza General. En el desarrollo de sus contenidos se aborda la aplicación general de una determinada disposición sin vincularla con un caso específico" 55 .

La circular DDU No 09 de 1996 señala que "siendo absolutamente imprescindible coordinar la inversión pública a fin de multiplicar sus efectos, el Plan Regional de Desarrollo Urbano [...] es el instrumento de planificación cuyo objetivo es la implantación en el territorio, de los criterios, objetivos y acuerdos básicos adoptados en relación con el devenir de la región, a través de un conjunto de decisiones y acciones. Entrega un marco obligatorio para los instrumentos de nivel más desagregado (intercomunal y comunal), bases para acuerdos sobre una agenda operativa y se relaciona con los instrumentos vecinos del mismo nivel". Agrega que "corresponde a las Secretarías Regionales de Vivienda y Urbanismo la responsabilidad respecto de la formulación del Plan Regional de Desarrollo Urbano, toda vez que ellas constituyen la expresión técnica de la autoridad regional" ${ }^{\prime 6}$. Sabiendo que dichas Secretarías Regionales son órganos desconcentrados del Ministerio de Vivienda y Urbanismo (en adelante MINVU), se puede hablar de coordinación y de tutela del Ministerio sobre los Gobiernos Regionales y, colateralmente, sobre las municipalidades.

\footnotetext{
52 Ya el DL No 573 de 1974 señalaba en su considerando $4^{\circ}$ letra d) que la "planificación del desarrollo" requiere la "integración de todos los sectores, mediante instituciones que aseguren su actuación en conjunto y no aisladamente”.

53 LEY No 20.990 de 2017.

54 Introducido por la Ley No 20.990, Artículo único, No 9.

55 Se puede consultar http://www.minvu.cl/opensite_20070213091658.aspx, consultado el 29.01.2017.

56 DDU9 Circ. 1083, 18.12.1996, p. 11.
} 


\subsection{LA COOPERACIÓN ADMINISTRATIVA COMO MODALIDAD DE RELACIÓN}

La cooperación no constituye un concepto nuevo en derecho público. En cambio, el fenómeno conoce un nuevo interés. La autoridad, la uniformidad, la jerarquía habrían abandonado su primacía en beneficio de la cooperación, la diversidad y el igualitarismo. La cooperación implica un trabajo en común. La palabra cooperación aparece una sola vez en la CPR, en la disposición transitoria No 24 , inc. 3 para referirse a las relaciones de "cooperación y asistencia entre las autoridades nacionales competentes y la Corte Penal Internacional" 57 . En ese contexto, el término de cooperación aquí utilizado se diferencia del sentido clásico del Estado cooperativo que considera las relaciones de cooperación entre

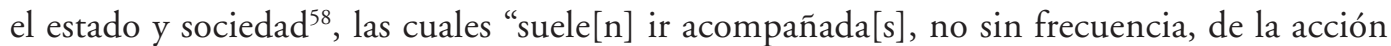
informativa" 59 .

El principio de cooperación se desenvuelve en el ámbito de las relaciones entre los distintos ET, tanto vertical como horizontalmente, y surge de la necesaria y evidente complementariedad del ejercicio de las propias competencias con la concurrencia en actuaciones comunes de los diferentes poderes públicos. En ese sentido, "el concepto de cooperación se configura [...] como un modo de ejercicio necesario o como un modo de articulación de las competencias conjuntamente con el de colaboración" ${ }^{\prime 0}$. A diferencia de la coordinación, la cooperación no es entonces una potestad o competencia, sino una modalidad de gestión administrativa. Su instrumento jurídico principal es el contrato administrativo y puede tomar las más diversas formas, dentro de las cuales tienen un lugar particular los convenios de colaboración y las fórmulas de asociación entre ET.

Ya al fin del siglo XIX, Maurice Hauriou había percibido el estrecho vínculo entre el procedimiento jurídico que constituye el contrato y la descentralización. Mas, en sus comentarios del fallo Administration des Pompes funèbres ${ }^{61}$, señalaba la relación entre una cierta profundización de la descentralización y la multiplicación de los acuerdos concluidos entre administraciones para asegurar la marcha de los servicios públicos. Hoy, el contrato está en todas partes de la Administración ${ }^{62}$. Eso tiene múltiples causas, pero no es fácil

\footnotetext{
57 En cambio, no es mencionada en la LOCGBAE, ni en la LOCM, como tampoco en la LBPA. En cambio, sí aparece en la LOCGAR. Una vez, en el art. 16, letra a), al mencionar el Ministerio de Planificación y Cooperación. Otra, en el mismo artículo, pero a la letra g) que menciona la participación "en acciones de cooperación internacional en la región, dentro de los marcos establecidos por los tratados y convenios que el Gobierno de Chile celebre al efecto y en conformidad a los procedimientos regulados en la legislación respectiva".

58 SChMidT-Assman (2003) p. 39. El autor pone el acento sobre la participación privada: "el principio de cooperación se basa en la convicción e iniciativa propia de los ciudadanos” p. 134. También: Bermúdez (2011) pp. 95-101. Sin desconocer ese aspecto, este no será estudiado de manera privilegiada y directamente. Primero, porque esa investigación se dirige a las relaciones entre entes públicos territoriales. Luego, porque los ciudadanos están considerados en los diferentes procedimientos normativos a los estadios de las diferentes consultas, referéndum y plebiscitos.

59 Schmidt-Assman (2003) p. 38.

60 Rodríguez-Arana (2006) p. 151.

${ }_{61}$ CE, 20 janv. 1899, S. 1899, 3, p. 113.

62 "Más aún -afirma Moraga- hoy en día es innegable que la Administración está actuando con más intensidad a través de pactos y acuerdos" Moraga (2015) p. 15.
} 
identificarlas todas, como tampoco jerarquizarlas ${ }^{63}$. Eso sí, explican el uso de técnicas más o menos contractuales y más o menos incluidas en el vocablo de "contractualización". Se puede decir que se trata de una noción sin contenido jurídico preciso, pero es preferible al de contratación pública. Las dos nociones no son equivalentes. El contrato es el acto mediante el cual dos o varias partes se comprometen una respecto a la(s) otra(s), con creación de obligaciones a cargo de al menos una de las partes ${ }^{64}$. La contractualization no solo evoca el acto jurídico, sino también una actividad o un modo de relación entre diferentes personas. Es una forma de institucionalización del contrato, una generalización de la relación contractual.

Institución de derecho privado al origen, el contrato constituye el modo jurídico de derecho común entre personas privadas, porque concreta la autonomía de la voluntad mediante la libertad de contratar y la de fijar el contenido de la convención. Es durante la época liberal que la teoría del contrato administrativo, instrumento jurídico de la relación entre personas públicas y personas privadas, fue forjada. El Estado quería limitar sus misiones. Incluso cuando debía intervenir en ámbitos nuevos, prefería entregar el cumplimiento práctico de esas misiones a empresas privadas, a cambio de reservarse un derecho de control o de dirección con el propósito de salvaguardar los fines del interés general. El contrato aparecía como la técnica idónea para esta colaboración ${ }^{65}$. Sin duda, un contrato celebrado entre dos personas públicas era inconcebible, pero las estructuras administrativas de la época solo lo consideraban un fenómeno excepcional.

Ahora bien, es forzoso constatar que la contractualización acompaña a menudo las leyes descentralizadoras. El incremento de las misiones del Estado, la multiplicación de los servicios personalizados, el desarrollo de las competencias territoriales, la introducción de nociones como concertación, conciliación, persuasión, dentro del aparato administrativo, han modificado el panorama público, a tal punto que el contrato se volvió una modalidad de relación entre el Estado y los ET. Es, hoy, una herramienta primordial de reforma administrativa. Resulta necesario recordar que toda la teoría general del contrato administrativo -en la medida en que existe una ${ }^{66}$ - es construida sobre el presupuesto de que se trata de un contrato entre una persona pública y un particular, persona física o jurídica ${ }^{67}$. El contrato es entonces presentado principalmente como alternativa al acto administrativo unilateral, otra herramienta de las relaciones público-privadas. Pero, se percibe no solo que los contratos entre personas públicas son posibles, sino que también son necesarios, particularmente en materia de descentralización. En efecto, en ausencia de poder jerárquico, el gobierno no debería poder imponerse a los ET, salvo hipótesis de intervenciones legislativas. Así, en sus relaciones cotidianas con los ET, el Estado solo puede usar la vía contractual que respeta,

\footnotetext{
63 La más fundamental es sin duda el cuestionamiento de la preeminencia del Estado central actuando por la vía del mandamiento y de la coacción, que acompaña un potente movimiento de descentralización.

64 Laubadère; Moderne y Delvolvé (1983).

65 Es bajo ese régimen que se realizará el equipamiento de Chile, a partir de la mitad el siglo XIX.

66 Ver, por ejemplo, Moraga (2015) pp. 26-32.

67 Incluso en un país como Alemania, que reconoció tardíamente la figura del contrato administrativo -por la ley de Procedimiento administrativo de 1976- , un autor del nivel de Schmidt-Assman privilegia el criterio subjetivo u orgánico. Schmidt-Assman (2003) p. 28.
} 
al menos en apariencia, las autonomías de aquellos. La situación es a fortiori la misma para los contratos entre ET, pues en ninguna parte se señala que las regiones ejercen una tutela (jurídica) sobre los municipios, e inversamente. Descartando los contratos de los ET con las empresas públicas, se pueden considerar los contratos entre el Estado y los ET, y luego los contratos entre estos últimos entre sí.

Los contratos entre Estado y ET son múltiples y autorizados por la propia $\mathrm{CPR}^{68}$, las leyes orgánicas municipales ${ }^{69}$ y regionales ${ }^{70}$. A modo de ejemplo, cuando el traspaso de competencias del gobierno central a los GORE, a que se refiere el artículo 67 pueda operar por la vía de un convenio, este será celebrado entre el gobierno regional y el ministerio respectivo, debiendo suscribirlo, además, el Ministro del Interior ${ }^{71}$. En materia de política económica y urbanística, los CP, como herramienta financiera, intervienen como instrumentos de la política económica del Estado.

La cooperación entre ET puede adoptar dos formas: la cooperación institucional, que se realiza en Chile mediante los acuerdos o convenios asociativos municipales ${ }^{72}$ y/o regionales, o la cooperación contractual $7^{73}$.

En cuanto a esa última, hemos visto que el artículo 115, inc. 3 CPR se aplica a las relaciones entre Estado, regiones y municipios. Las relaciones entre regiones y las relaciones entre municipios fluyen a menudo de los acuerdos de cooperación institucional, pero no siempre. Así de los CP, pero es también - por ejemplo- el artículo 4 LOCM relativo al conjunto de las competencias no exclusivas, que estas "podrán desarrollar, directamente o con otros órganos de la Administración del Estado".

Lo que está nítidamente confirmado por el art. 8 LOCM, según el cual "para el cumplimiento de sus funciones, las municipalidades podrán celebrar convenios con otros órganos de la Administración del Estado en las condiciones que señale la ley respectiva, sin alterar las atribuciones y funciones que corresponden a los municipios. Asimismo, a fin de atender las necesidades de la comunidad local, las municipalidades podrán celebrar contratos que impliquen la ejecución de acciones determinadas".

Pero, el examen de la contractualización pública debe ir más allá de esas manifestaciones claras e identificar otras hipótesis. Por ejemplo, la posibilidad de "otorgar subvenciones y aportes para fines específicos a personas jurídicas de carácter público o privado, sin fines de lucro, que colaboren directamente en el cumplimiento de sus

\footnotetext{
68 Art. 115 , inc. 4.

69 Art. 10 LOCM.

70 Art. 81 LOCGAR.

71 Art. 107 LOCGAR.

72 Art. 118 inc. 6 CPR, recogido por el artículo 5 LOCM y el párrafo 2 del título VI de la misma ley: para las corporaciones y fundaciones municipales (art. 129 a 136 LOCM). Para las asociaciones de municipalidades (artículos 137 a 150 LOCM). Ver también: Decreto 1161 que establece el Reglamento para la aplicación de las normas de la LOCM, referidas a las asociaciones municipales con personalidad jurídica.

73 LOCGAR, CAPÍTULO VII, del Asociativismo Regional, arts. 100 a 104. Corresponde en gran parte a las condiciones de las corporaciones y fundaciones municipales. Pero, a diferencia de estas, la LOCGAR no precisa que esas corporaciones y fundaciones regionales puedan ser formadas entre regiones o con otras entidades del sector público, sino solamente con otras personas jurídicas. Lo que no parece impedirlo, aunque la vocación intrarregional sea evidente.
} 
funciones"74. U otro, el hecho de que "dos o más municipalidades podrán convenir que un mismo funcionario ejerza, simultáneamente, labores análogas en todas ellas"75. En la misma línea, el artículo 155 LOCM prevé que instalada una nueva municipalidad, el o los municipios originarios le traspasarán en el plazo de seis meses, los servicios municipales y sus establecimientos o sedes, ubicados en el territorio comunal que esté a su cargo. Este traspaso se efectuará en forma definitiva, mediante la celebración de un convenio entre las respectivas municipalidades ${ }^{76}$, el cual deberá ser sancionado por decreto de los respectivos alcaldes ${ }^{77}$. Otro caso, el que se produce cuando una región pone a disposición de las municipalidades -cuando lo solicitan- sus servicios para la elaboración de sus documentos urbanísticos $^{78}$. Hoy la cooperación contractual es casi tan importante como la cooperación institucional. Las dos fórmulas, más que competir, se combinan.

\subsection{LA PARTICIPACIÓN COMO MECANISMO DE LEGITIMACIÓN}

La legitimación de la actuación de las autoridades públicas pasa primero por la elección que permite representar los intereses de un grupo, así como sentar la base de su autonomía. En efecto, la existencia -constatada o reconocida- de una capacidad a la representación es el primer elemento, el dato necesario para la constitución y la definición de cualquier grupo. El que tiene una relación "activa" con la representación, está en posición de sujeto, y esa posición es la fuente de su autonomía ${ }^{79}$.

La Administración central debe respetar la autonomía de los ET, pero también debe fomentar la expresión de intereses. La elección del conjunto de las autoridades administrativas, es reforzada por los mecanismos de participación ciudadana. En lo que nos interesa, la participación seguramente implica la transparencia y la publicidad, pero importa también una "procedimentalización" general de las relaciones sociales. Esta puede ser considerada desde el punto de vista de la ciudadanía, como el de los actores públicos. Estos últimos nos interesan aquí más por razones vinculadas a las modalidades de dicha participación ciudadana. En el caso de una participación individual, corresponde más a una preocupación "egoísta” y no colabora a la definición y la aplicación de las políticas públicas territoriales. En el segundo caso, los ciudadanos sí pueden intervenir en ellas y se inscribe en un movimiento general de participación colectiva o difusa. Si bien puede derivar del principio constitucional de "participación ciudadana en la vida nacional" ${ }^{80}$, ha sido transcrita en la LOCGBAE ${ }^{81}$ mediante el título IV “De la participación ciudadana en la gestión pública”" . Podemos destacar en particular el deber de cada órgano de la Administración

\footnotetext{
74 Art. 5 g) LOCM.

75 Art. 44 LOCM.

76 Art. 156, inc. 1 LOCM.

77 Art. 156, inc. 6.

78 Art. 16 e) LOCGAR.

79 MAzÈres (1990) p. 625.

80 Art. $1^{\circ}$, inciso final, CPR.

81 Ley 20.500, de 2011.

82 Arts. 69 a 75, LOCGBAE.
} 
del Estado de establecer las modalidades formales y específicas de participación que tendrán las personas y organizaciones en el ámbito de su competencia ${ }^{83}$. Estas disposiciones están recogidas en las normas sectoriales, sobre todo en el ámbito municipal y medioambiental. Al respecto, se deberá establecer en cada municipalidad, una ordenanza relativa a las modalidades de participación de la ciudadanía local ${ }^{84}$. De ese modo, poco a poco, se inscribe la participación ciudadana en la formulación de normas generales y abstractas ${ }^{85}$. Sin embargo, tenga o no fuerza vinculante ${ }^{86}$, la participación ciudadana está canalizada por los íteres procedimentales definidos por los poderes públicos, lo que, en definitiva, remite a problemas de competencia de los actores públicos. Los trámites procedimentales articulan la "participación" de los distintos órganos administrativos sobre una determinada materia y según el alcance de su competencia. El procedimiento, como instrumento técnico, facilita la intervención -a veces abrumadora- de varios actores públicos, con o sin participación ciudadana, mediante la articulación de diversas herramientas, como son los informes previos, las aprobaciones, o las consultas, etc. Los trámites de procedimiento administrativo son herramientas de coordinación y de cooperación administrativa, en el sentido que la ley general en la materia, la LOCGBAE, impone hacer efectivo el principio de coordinación administrativa ${ }^{87}$. En virtud de este, "los órganos de la Administración del Estado deberán cumplir sus cometidos coordinadamente y propender a la unidad de acción, evitando la duplicación o interferencia de funciones" 88 .

\section{LOS INSTRUMENTOS DE LA ATC: INCERTIDUMBRES Y DESAFÍOS JURÍDICOS}

\subsection{El Plan Regional de Ordenamiento Territorial (PROT): ¿¿del método al INSTRUMENTO JURÍDICO? \\ Conforme el artículo 3 LOCGBAE, las diferentes administraciones territoriales} tienen por misión -cada una a su nivel y según las atribuciones que le confiere la Constitución y la ley- elaborar, aprobar, ejecutar y controlar políticas, planes, programas y acciones para la consecución del bien común. En cuanto a su naturaleza jurídica, el PROT no es un instrumento de planificación territorial, puesto que no está previsto por la LGUC ${ }^{89}$. En esas condiciones: "es un método concreto para realizar ordenamiento a nivel regional. Se trata de un instrumento de mayor amplitud y generalización que los de planificación sectorial vigentes y a una escala que posibilitará orientar y compatibilizar los mismos, en-

\footnotetext{
83 Art. 70 LOCGBAE.

84 Art. 93 LOCM.

85 Ver, por ejemplo, los arts. 7 bis y 7 ter LBGMA.

86 Ver art. 118-5 ${ }^{\circ}$ CPR que precisa que la LOCM señalará las materias de competencia municipal que el alcalde, con acuerdo del concejo o a requerimiento de los $2 / 3$ de los concejales en ejercicio, o de la proporción de ciudadanos que establezca la ley, someterá a consulta no vinculante o a plebiscito, así como las oportunidades, forma de la convocatoria y efectos.

87 Art. 3, inc. $2^{\circ}$.

88 Art. $5^{\circ}$, inc. $2^{\circ}$.

89 Dictamen CGR No 59.316 de 2006.
} 
tre ellos. [...] En cuanto plan, estará mucho más cerca de la práctica planificadora y de la toma de decisiones políticas que del análisis científico-técnico del territorio. [...] Más que un instrumento restrictivo, se trata entonces de un instrumento orientador de usos que [...] posibilitará evaluar la compatibilidad entre estos $-\mathrm{y}$ entre ellos y la sustentabilidad ambiental-, con el objeto de establecer condiciones de actuación, uso e intervención, en virtud de los diferentes intereses por el uso del territorio" ${ }^{\circ 0}$. Es un documento indicativo, prospectivo, y entonces no vinculante. Sin embargo, ignorar -como lo hace la CGR de manera equivocada en su dictamen No 59.316 de 2006- que el PROT entra en el campo de competencias de los GORE ${ }^{11}$ y que entonces puede ser sancionado por reglamento regional, pone en evidencia la labor centralizadora de la $\mathrm{CGR}^{92}$, así como la necesidad de una intervención legislativa. Efectivamente, no estando regulado, pero siendo al mismo tiempo el producto de un procedimiento administrativo, se presenta al igual que los PRDU como un instrumento no regulador, que no contiene normas.

\subsection{Los Convenios de Programación (CP): ¿¿De la vía contractual al genuino CONTRATO?}

Los convenios interadministrativos en general, y los $\mathrm{CP}^{93}$ en particular, nacen de la necesidad de solucionar la dificultad de llevar a cabo las políticas públicas de manera aislada, que dependan del Estado o de otras colectividades: ordenamiento del territorio, políticas sociales, acogida e integración de los extranjeros, implican acciones conjuntas y financiamientos cruzados que deben ser coordinados. El Estado intenta resolver esas dificultades, de modo cada vez más frecuente mediante la fórmula del convenio ${ }^{94}$.

\subsubsection{Naturaleza jurídica de los CP: una senda contractual}

El CP no es un contrato administrativo sometido a la Ley de Compras, puesto que quedan excluidos de su aplicación los convenios que celebren entre sí los organismos públicos enumerados en el artículo $2^{\circ}$, inciso primero, del decreto ley No 1.263 , de 1975, Ley Orgánica de Administración Financiera del Estado. Tampoco es regido por las normativas relativas a las obras públicas en general (concesión, construcción, ejecución). Ahora bien, un contrato entre dos personas públicas, que traduce el encuentro de dos gestiones públi-

\footnotetext{
90 SUBDERE (2011) p. 5.

91 Arts. 14, 16 y 17 LOCGAR.

92 Pantoja (1994) p. 240.

93 Art. 81, inc. 1 LOCGAR: "Los convenios de programación a que se refiere el inciso cuarto del artículo 104 (hoy 115) de la Constitución Política de la República son acuerdos formales entre uno o más gobiernos regionales y uno o más ministerios, que definen las acciones relacionadas con los proyectos de inversión que ellos concuerdan en realizar dentro de un plazo determinado. Estos convenios deberán especificar el o los proyectos sobre los cuales se apliquen, las responsabilidades y obligaciones de las partes, las metas por cumplir, los procedimientos de evaluación y las normas de revocabilidad. Los convenios de programación deberán incluir, cuando corresponda, cláusulas que permitan reasignar recursos entre proyectos.”

94 OCDE (2009) recalca los acuerdos de gobernanza -mediante CP- que permiten una mayor colaboración en los distintos niveles de Gobierno, y entre distintos actores presentes en un territorio, con el fin de realizar en conjunto políticas con impacto territorial capaces de planificar y coordinar estrategias regionales a largo plazo.
} 
cas, debería ser calificado de contrato administrativo ${ }^{95}$, salvo calificación legal expresa en contra ${ }^{96}$. Pero es solo una simple presunción, que admite prueba en contrario, si el contrato establece entre las personas públicas relaciones de derecho privado. En lo que nos interesa, en los convenios de programación se podrán incorporar entidades privadas cuyo concurso o aporte se estime necesario ${ }^{97}$. De manera general, la distinción procesal francesa entre contrato administrativo y contrato de derecho privado no sirve, pues todos los contratos son controlados al fin y al cabo por los tribunales ordinarios de justicia. Así, los convenios interadministrativos "caen dentro de la materia (de la contratación administrativa)"98, pero "según la mayor o menor intensidad del régimen de Derecho Público, los diversos contratos que celebra la Administración pueden ser más próximos al Derecho Administrativo o al Derecho Privado"'99.

A priori, la suscripción de una convención implica la libertad de contratar y la libertad de determinar las obligaciones reciprocas, el contenido del contrato. La realidad es muy diferente. La cooperación regularmente es impuesta, y los ET están obligados a contratar. Por otro lado, el contenido del convenio es predeterminado por el gobierno central. En este sentido, la situación de la región respecto a los CP es elocuente. En teoría, la región es libre de suscribir o no un CP con el Estado. En la práctica, todas lo hacen: considerando sus recursos, no pueden hacer nada sin el apoyo material y financiero del Estado. El CP se presenta entonces como el procedimiento mediante el cual el Estado obtiene de las regiones su adhesión a sus políticas. Es efectivamente una de las funciones generales del gobierno regional, la de "elaborar y aprobar las políticas, planes y programas de desarrollo de la región, los que deberá ajustar a la política nacional de desarrollo y al presupuesto de la Nación" ${ }^{100}$. Los CP no tienen otra finalidad que orientar las regiones hacia la realización de objetivos compatibles con el plan de la nación ${ }^{101}$. Entonces, el CP ejerce una función de recentralización frente a regiones con un débil margen de discusión. El conjunto de esos límites conduce a considerar este tipo de convenio como una especie de contrato de adhesión. Eso es verdad para los contratos entre Estado y ET, así como para los celebrados entre estos últimos ${ }^{102}$. En esa línea, la teoría de los actos mixtos se apoya sobre la idea matriz de la concesión de servicios públicos. Considera que las convenciones serían de forma contractual, pero de contenido reglamentario. El empaque contractual solo contendría en realidad una adición de disposiciones de naturaleza reglamentaria. Los socios son teóricamente iguales, pero en la práctica, unos prevalecen sobre los otros.

\footnotetext{
95 Dictamen CGR No 46.532 de 2000.

96 Cf. supra las fórmulas asociativas de municipalidades o regiones.

97 Art. 81, inc. 2 LOCGAR.

98 Moraga (2015) p. 18

99 Moraga (2015) p. 55.

100 Art. 16 a) inc. 1 LOCGAR.

101 Art. 16 a) inc. 1 LOCGAR.

102 Según que, si el firmante de un acuerdo con la región sea alcalde de un municipio de 5.000 o de 100.000 habitantes, según que ha sido ministro, diputado, senador (o no), etc. es evidente que el contenido del acuerdo no será el mismo, como tampoco sus efectos.
} 
El CP contiene numerosas declaraciones de intención, un catálogo de medidas preparatorias u objetivos, pero para ser efectivos, necesitan medidas administrativas de materialización. En cuanto a las obligaciones financieras, están sometidas al principio de anualidad presupuestaria ${ }^{103}$. Los convenios tienen pocos efectos jurídicos inmediatos. Por ello, aunque esté citado en estudios sobre contratación administrativa, no es ni un contrato administrativo, ni siquiera es un contrato, puesto que no vincula a las partes ${ }^{104}$. Es entonces necesario "incorporar (al CP) normas destinadas a materializar la obligatoriedad de estos convenios. En este ámbito, se precisa que las normas sobre exigibilidad de convenios de programación serán aplicables tanto a los ministerios como a los gobiernos regionales, cuyos presupuestos deben ser aprobados también por el Congreso Nacional"105.

El CP es un instrumento financiero que engloba varios tipos de contratos. Como lo señala el art. 81, inc. 1 LOCGAR, definen las acciones relacionadas con los proyectos de inversión. Los contratos de la Administración solo aparecen en un segundo tiempo al materializar dichos proyectos. Pero el CP es un modelo para otros tipos de convenio. Constituye la matriz de los que están por venir. Efectivamente, el mismo proyecto de ley propone la creación de Convenios de Programación Territoriales y de Convenios Mandato. Los primeros podrán ser celebrados por los gobiernos regionales con una o más Municipalidades, con carácter anual o plurianual, y están destinados a formalizar acuerdos para la implementación de proyectos de impacto comunal o intercomunal. Los segundos se inspiran en los "convenios mandato", reconocidos en la ley $\mathrm{N}^{\circ} 18.091^{106}$. Conforme el artículo 16, inc. 4 de dicha ley, los ET pueden "encomendar a los organismos técnicos del Estado, por medio de un mandato completo e irrevocable, la licitación, adjudicación, celebración de los contratos y la ejecución de estudios, proyección, construcción y conservación de obras de cualquier naturaleza que hayan sido previamente identificadas. El cumplimiento del mandato quedará sujeto a los procedimientos, normas técnicas y reglamentarias de que dispone el organismo mandatario para el desarrollo de sus propias actividades". Señala Moraga que este tipo de convenio aumenta la eficiencia y eficacia de la contratación, al tiempo de facilitar la coordinación de los entes que participan en el sistema” y que su conveniencia es justificada por el "mayor peso relativo que tiene uno de ellos en materia presupuestarias o de recursos materiales y personales, pero, también, por sus regímenes legales"107. No es posible extrapolar de sus fechas de nacimiento y menos aún de los detalles, pues numerosos

\footnotetext{
103 Precht (1993).

104 El Dictamen CGR N¹5.978 de 2010 señala que "una invariable jurisprudencia de esta Entidad de Control ha señalado que, salvo norma legal expresa, entre órganos de la Administración del Estado no existe una obligación genérica de garantizar y asegurar el cumplimiento de los compromisos que contraigan en virtud de los convenios que celebran". Pero, qué pasará con los actores privados, puesto que "a los convenios de programación se podrán incorporar otras entidades públicas o privadas, nacionales, regionales o locales, cuyo concurso o aporte se estime necesario para la mayor eficiencia en la ejecución del referido convenio de programación" (art. 81 inc. 2 LOCGAR). En el mismo dictamen, la CGR indicó que "el deber de garantizar las obligaciones de un convenio debe interpretarse en el sentido que ello es únicamente aplicable a entidades privadas".

105 Boletín $\mathrm{N}^{\circ} 7963-06$ que introduce modificaciones a la ley $\mathrm{n}^{\circ} 19.175$, orgánica constitucional sobre gobierno y administración regional, profundizando la regionalización del país.

106 LEY No 18.091 de1 981.

107 Moraga (2015) p. 64.
} 
proyectos han sido enterrados sin pena ni gloria, pero, sin lugar a duda, el futuro de la descentralización no podrá ignorar esos instrumentos jurídicos.

\subsubsection{Significaciones de la figura del Convenio}

Quizás, el concepto convenio tiene por objeto superar lo que puede tener de rígida la noción de contrato. La "contractualización" busca borrar las reminiscencias a la idea de jerarquía entre entes públicos o cualquiera idea de oposición si se trata de asociar a la vez entes públicos y personas privadas. Evoca una ideología igualitaria y consensual. Añora también la alianza para lograr un objetivo común, la solidaridad entre los socios. Así, los $\mathrm{CP}$ cumplen una doble función, como instrumento de financiamiento y como acuerdo de gobernanza multinivel ${ }^{108}$. Pero esa tendencia plantea algunos problemas político-jurídicos.

Los convenios entre ET se presentan a menudo como un sustituto de las fórmulas institucionales de cooperación, por su rigidez, pero sobre todo por sus escasas posibilidades de acción ${ }^{109}$.

Significan también una alteración de la repartición de competencias, cuestionando el trabajo del legislador en materia de descentralización. A veces, la ampliación de las competencias de los ET procede del legislador, pero regularmente se hace mediante la convención y, más que una posibilidad para las personas públicas, el contrato se vuelve, a veces, una necesidad. Las modalidades contractuales de transferencias de competencias pueden realizarse según dos técnicas que pueden ser complementarias. Los ET pueden asociarse para el ejercicio de sus competencias creando asociaciones o fundaciones según la normativa en vigor. Esa fórmula si bien es flexible, plantea un problema: dos órganos públicos se ponen de acuerdo para llevar una política pública a cabo, pero su reunión conforma un ente de derecho privado, y "el personal que labore en las corporaciones y fundaciones de participación municipal se rige por las normas laborales y previsionales del sector privado" ${ }^{110}$. Los ET pueden también celebrar entre ellos convenciones mediante las cuales se comprometen a poner a disposición de otros entes sus servicios y medios a fin de facilitar el ejercicio de sus competencias ${ }^{111}$. Puede resultar en efecto, que los traspasos del personal necesario para el ejercicio de algunas nuevas competencias como también el ejercicio mismo de estas, solo serán posibles si previamente han sido suscritos convenios entre ET interesados. El contrato se transforma en la herramienta para aplicar la norma legislativa o constitucional, función generalmente reservada a los decretos de aplicación, con los cuales entra en competencia $^{112}$.

\footnotetext{
108 Uarac y Escalona (2012) p. 57.

109 Cf. párrafo 2, título VI LOCM.

110 Art. 134 LOCM.

111 Es el caso, por ejemplo del Artículo 18 LOCM: "Dos o más municipalidades, de aquellas a que alude el inciso primero del artículo anterior, podrán, mediante convenio celebrado al efecto y cuyo eventual desahucio unilateral no producirá consecuencias sino hasta el subsiguiente año presupuestario, compartir entre sí una misma unidad, excluidas la secretaría municipal, el administrador municipal y la unidad de control, con el objeto de lograr un mejor aprovechamiento de los recursos humanos disponibles".

112 Chapus (2001) p. 297, nº 418.
} 
En fin, los CP muestran como la vía contractual puede ser un medio -desviado, pero eficaz- de control del Estado sobre los ET. Primero, es el Estado que fija la lista de las materias o ámbitos contractualizables. De cierta manera, se podría decir que el Estado tiene la posibilidad de condicionar sus créditos de inversión privilegiando al final, los ET que aceptaran espontáneamente participar plenamente al financiamiento de los proyectos del Estado.

La cuestión que se plantea entonces, es saber si la difusión de las prácticas de índole contractual no es una forma disfrazada y refinada de tutela: bajo la apariencia de compromisos recíprocos, se obligan las autoridades territoriales a adherir a las políticas del Estado para beneficiarse de sus financiamientos. Esos convenios, teóricamente respetuosos de la autonomía del contratante, sustituirían el abandono de la supervigilancia del Estado central sobre los ET. No es el control clásico sobre los actos o las personas, sino un control global sobre una política particular. No se trata de impedir o bloquear. Se trata de incentivar al ET a confluir hacia las políticas estatales. Para ello, el acto administrativo unilateral resulta inadecuado, en cambio la vía contractual es la idónea. A modo ejemplar, el conjunto de las acciones llevadas en los territorios da lugar a financiamientos cruzados, lo que conduce a oscurecer la repartición de las competencias, al mismo tiempo que se exige transparencia en todo. El cofinanciamiento, en general Estado-región, se realiza independientemente de saber cuál es la colectividad titular de la competencia en cuestión. De hecho, el uso del FNDR y los aportes del MINVU o del Ministerio de Obras Públicas (MOP) demuestran que la totalidad de los convenios de programación son en realidad financiados por el gobierno central ${ }^{113}$, quien apoyará las acciones regionales conformes a sus propias orientaciones. Por último, en ciertos casos, esa modalidad de ATC puede conducir a una "renacionalización" del ejercicio de las competencias transferidas.

\section{CONCLUSIÓN}

Las acciones de los entes públicos sobre el territorio y la complejidad de sus relaciones imponen buscar una clarificación necesaria de los procedimientos administrativos en los cuales las exigencias de coordinación, cooperación y participación son hoy imprescindibles. En ese contexto, la ATC, entendida como el ejercicio en común de competencias por parte de los diferentes entes públicos territoriales, es el crisol de varias novedades jurídicas que están por venir en el derecho chileno: efecto vinculante de los PROT y de los Convenios de programación, creación de las Áreas Metropolitanas, generalización de la figura de los convenios, entre otros instrumentos. Una reflexión jurídica se revela entonces indispensable.

Primero, se debe tomar conciencia que hoy ninguna competencia descentralizada puede ser real y seriamente calificada de exclusiva, pues exige la intervención de diferentes actores a varios niveles o momentos de la aplicación de las políticas públicas sobre los territorios. Luego, el derecho debe organizar la coordinación de las acciones y formalizar

\footnotetext{
$113 \mathrm{http} / /$ www.dirplan.cl/direccionesregionales/conveniosdeprogramacion/Documents/Informe_Convenios_ de_Programacion_2013.pdf
} 
el arbitraje del Estado y las responsabilidades de cada socio con toda claridad para disipar las indeterminaciones de la coadministración. Sobre ese último punto, siempre hay y debe haber una parte del mandato que se exprese mediante la ley o el reglamento, pues no se puede gobernar solo por el contrato ${ }^{114}$. En ese sentido, el legislador debe diseñar de manera más fina los procedimientos del ejercicio mismo de las competencias descentralizadas, considerando el peso respectivo de los diferentes intervinientes y de sus actos, tales como el derecho o el poder iniciativa, la obligación de consulta, la obligación de seguir o no los dictámenes, las posibilidades de veto, las responsabilidades, etc. En definitiva, pensar de manera sería la articulación de los actores de la descentralización, y de sus actos jurídicos respectivos, dentro del marco de un modelo de acto que no sea ni puramente unilateral ni contractual en el sentido estricto del contrato administrativo. Eso implica repensar las políticas territoriales desde el doble punto de vista de la cooperación institucional y de la cooperación funcional ${ }^{115}$.

\section{BIBLIOGRAFÍA CITADA}

Astorga Jorquera, Eduardo (2006): Derecho ambiental chileno. Parte general (Santiago, LexisNexis).

Auby, Jean-Bernard (2009): "La question des compétences locales, vue d'ailleurs", en BRIsSON, Jean-François (dir.), Les transferts de compétences de l'État aux collectivités locales (Paris, L'Harmattan) pp. 17-19.

Aylwin Azócar, Patricio (1959): Derecho Administrativo, Tomo 1 (Santiago, Editorial Universitaria S.A.).

Baudin-Culliere, Frédéric (1995): Principe de subsidiarité et administration locale (Paris, L.G.D.J.).

Bermúdez Soto, Jorge (2011): Derecho administrativo general (Santiago, LegalPublishing, segunda edición).

Bermúdez Soto, Jorge (2014): Fundamentos del Derecho ambiental en Chile (Valparaíso, Ediciones Universitarias de Valparaíso, PUCV, segunda edición).

Boвbio, Norberto (2007): Teoría general del Derecho (Bogotá, Editorial Temis, tercera edición)

Boletín No 7963-06. Inicia un proyecto de ley que introduce modificaciones a la ley $n^{\circ} 19.175$, orgánica constitucional sobre gobierno y administración regional, profundizando la regionalización del pais.

BRIANT, Vincent de (2009): L'action commune en droit des collectivités territoriales, contribution à l'étude des compétences exercées en commun par l'État et les collectivités territoriales (Paris, L'Harmattan).

Carta Europea de Ordenación del Territorio (1983).

\footnotetext{
114 En ese sentido, Moraga (2015) p. 17.

115 Ambos aspectos serán objeto de otros trabajos que constituyen futuros desarrollos de esa investigación Fondecyt.
} 
Chapus, René (2001) : Droit administratif général, Tomo 1 (Paris, Monchrestien, decimoquinta edición).

Cordero Quinzacara, Eduardo (2007): "El derecho urbanístico, los instrumentos de planificación territorial y el régimen jurídico de los bienes públicos”, Revista de Derecho, Valparaíso, No 29: pp. 269-298.

Comisión Asesora Presidencial en Descentralización y Desarrollo Regional (2014): Propuesta de Política de Estado y Agenda para la Descentralización y el Desarrollo Territorial de Chile. Hacia un Pais Desarrollado y Justo.

Guzmán Rosen, Rodrigo (2010): La Regulación Constitucional del Ambiente en Chile. Aspectos sustantivos y adjetivos. Historia, doctrina y jurisprudencia (Santiago, Editorial AbeledoPerrot/LegalPublishing, segunda edición).

Delooz, Benoît (2015): "El dilema de la regionalización chilena: ¿̇más desconcentralización o "auténtica" autonomía regional?", en: BocksANG, Gabriel y LARA ArroYo, José Luis (coord.) Administración Territorial de Chile (Santiago, Thomson Reuters) pp. 107130.

Derosier, Jean-Philippe (2007): "La dialectique centralisation/décentralisation - Recherches sur le caractère dynamique du principe de subsidiarité", Revue internationale de droit comparé, $\mathrm{N}^{\circ} 1$ : pp. 107-140.

Delamaza, Gonzalo y Thayer, Luis (2016): "Percepciones políticas y prácticas de participación como instrumento para la gobernanza de los territorios. Un análisis comparado de escalas territoriales en la macrorregión sur de Chile", Revista EURE, Vol. 42, No127: pp. 137-158.

Laubadère, André de; Moderne, Franck y Delvolvé, Pierre (1983): Traité des contrats administratifs, (Paris, LGDJ).

Mallea Álvarez, María Isabel (2008): “Ordenamiento territorial y la dimensión ambiental de los instrumentos de planificación en Chile”, Ecosostenible, No 40: pp. 40-51.

MAZÈres, Jean-Arnaud (1990): "Les collectivités locales et la représentation. Essai de problématique élémentaire", Revue de Droit Public, No 5: pp. 607-642.

Ministerio de Obras Públicas/Dirección de Planeamiento/Subdirección de Planificación Estratégica (2013): Informe Convenios de Programación Año 2013. Disponible en: http://www.dirplan.cl/direccionesregionales/conveniosdeprogramacion/Documents/ Informe_Convenios_de_Programacion_2013.pdf. Fecha de consulta: 1 de febrero de 2017.

Moraga Klenner, Claudio (2015): Contratación administrativa (Santiago, Editorial Jurídica de Chile).

Moreau, Jacques (2004): Administration régionale, départementale et municipale, (Paris, Dalloz, $14^{\text {ème éd.) }}$

Organización PARA la COOPERACión y el desarrollo eConómicos (2009): Estudios Territorial de la OCDE. Chile. Disponible en: http://www.ministeriodesarrollosocial.gob.cl/ btca/txtcompleto/est.ocdeCh.pdf. Fecha de consulta: 15 de octubre de 2017.

Pantoja BauzÁ, Rolando (1994): El Derecho administrativo. Clasicismo y Modernidad (Santiago, Editorial Jurídica de Chile). 
Pantoja BauzÁ, Rolando (2004): La organización administrativa del Estado (Santiago, Editorial Jurídica de Chile).

Pontier, Jean-Marie (1978): L'État et les collectivités locales (Paris, L.G.D.J., «Bibliothèque du droit public », T.CXXVII).

Precht, Jorge (1993): "Principios jurídicos de hacienda pública", Revista Chilena de Derecho, 20, vol. No 2-3: pp. 775-794.

Rajevic Mosler, Enrique Petar (2000): "Derecho y Legislación Urbanística en Chile", Revista de Derecho Administrativo Económico, Vol. II, No2: pp. 527-548.

Rajevic Mosler, Enrique Petar (2008): "La potestad organizatoria en el Derecho chileno: teoría y práctica”, en Cordero Quinzacara, Eduardo (coord.), Estudios sobre la Ley Orgánica Constitucional de Bases Generales de la Administración del Estado (Santiago de Chile, Universidad de Antofagasta) pp. 173-199.

RodríguEZ-ArAna, Jaime (2006): "Modelo territorial y principio de cooperación", REALA, No 300-301: pp. 139-164.

Rojas Calderón, Christian (2012): "Instrumentos de gestión ambiental en Chile. En especial el Sistema de Evaluación de Impacto Ambiental (SEIA)”, en PINTO, Mauricio y Martin, Liber (dir.), La evaluación de impacto ambiental y su régimen jurídico (Buenos Aires, Lajouane) pp. 233-269.

SÁnchez Morón, Miguel (1992): "La coordinación administrativa como concepto jurídico", Revista de Documentación Administrativa, No 230-231: pp. 11-30.

Schmidt-Assmann, Eberhard (2003): La teoría general del Derecho Administrativo como sistema (Madrid, Marcial Pons).

Silva Cima, Enrique (1994): Derecho Administrativo Chileno y Comparado, Tomo III. El control público (Santiago, Editorial Jurídica de Chile).

Subdere (2002): Diccionario de Administración Pública Chilena (Santiago, LOM Ediciones, segunda edición.).

Subdere (2011): Plan de Ordenamiento Territorial: Contenido y Procedimientos (Santiago, 1a edición). Disponible en: http://www.subdere.gov.cl/sites/default/files/articles-82539_recurso_1.pdf. Fecha de consulta: 1 de diciembre de 2016.

Uarac González, Leidi y Escalona-Ulloa, Miguel (2012): "Factores vinculantes entre Convenios de Programación en las Regiones de Los Lagos, Los Ríos y La Araucanía, y un instrumento de Planificación Territorial”, Revista Lider, Vol. 21: pp. 51-76.

Varela del Solar, Jorge Luis (2010): "Derecho ambiental como derecho público. Instrumentos de la política ambiental", Actualidad Jurídica, No 22: pp. 377-410.

Villagrán Abarzúa, Marcelo (2013): "Bases de la institucionalidad municipal chilena", en Chacón Romero, Andrés (edit.) Análisis y perspectivas del Derecho municipal chileno (Santiago, Instituto Chileno de Estudios Municipales) pp. 192-217.

Wollmann, Hermann (2006): "La décentralisation française vue d'ailleurs", en La décentralisation en mouvement, Ministère de l'Intérieur et de l'Aménagement du Territoire, les travaux du centre d'études et prospective (Paris, La Documentation française) pp. 121138. 


\section{NORMAS CITADAS}

Decreto Nº 100 (25/09/2005), Constitución Política de la República de Chile.

Ley No 18.575 (05/12/1986), Ley Orgánica Constitucional de Bases Generales de la Administración del Estado.

LEY No $19.175(8 / 11 / 2005$, Orgánica Constitucional sobre Gobierno y Administración Regional.

Ley No 18.695 (26/07/2006), Orgánica Constitucional de Municipalidades.

Ley No 20.990 (05/06/2017), Dispone la Elección Popular del Órgano Ejecutivo del Gobierno Regional.

Decreto Ley No 1.263 (21/11/1975), Ley Orgánica de Administración Financiera del Estado

Ley Nº 19.300 (09/03/1994), sobre Bases Generales del Medio Ambiente.

LeY No 20.500 (16/02/2011), Sobre Asociaciones y Participación Ciudadana en la Gestión Pública.

DeCreto Ley No 573 (12/07/1974), Estatuto del Gobierno y Administración interiores del Estado.

LeY No458 (13/04/1976), General de Urbanismo y Construcciones.

Decreto No47 (05/06/1992), del Ministerio de Vivienda y Urbanismo, Fija Nuevo Texto de la Ordenanza General de Urbanismo y Construcciones

Circular DDU9 No 1083 (18/12/1996).

LEY No 18.091 (30.12.1981), Establece Normas complementarias de Incidencia Presupuestaria, de Personal y de Administración financiera.

\section{JURISPRUDENCIA CITADA}

Dictamen CGR N¹5.978, de 2010.

Dictamen CGR No 59.316, de 2006.

Dictamen CGR No 46.532, de 2000.

Conseil d'État, 20 janv. 1899, Administration des Pompes funèbres, S. 1899, note Hauriou. 
